\title{
IMPACTS OF PRICE TRANSPARENCY ON CONSUMER PRICE FAIRNESS PERSPECTIONS AND BEHAVIORAL INTENTIONS
}

\author{
Gopalkrishnan Iyer, Florida Atlantic University, USA \\ Dhruv Grewal, Babson College, USA \\ Sandra Rothenberger, University of Innsbruck, Austria
}

\begin{abstract}
The authors propose that price transparency plays an important role in customers' judgments of whether prices offered by sellers are fair. Cognitive fairness judgments require a certain amount of information processing, so more information and transparency about prices should affect the outcome of fairness judgments. The greater the price transparency, i.e., the greater the information that consumers have on the seller's prices, the higher will be their perceptions of price fairness. Price fairness in turn leads to more favorable evaluations of satisfaction perceptions and increases customers' behavioral intentions to repurchase and recommend. The impact of price transparency on price fairness perceptions and the resulting effects on satisfaction and behavioral intentions are tested through a structural equation model using a sample of 1,459 passengers of a major European transport services company.
\end{abstract}

References available upon request 